\title{
Descentralização do Programa de Alimentação Escolar em Cuiabá: 1993-1996
}

\author{
Decentralization of the School-Lunch Program in \\ Cuiabá: 1993-1996
}

Maria Angélica dos Santos SPINELLI ${ }^{1}$

Ana Maria CANESQUI²

\section{R E S U M O}

O artigo trata da avaliação do processo de implementação do programa descentralizado (municipalizado) de alimentação escolar em Cuiabá, no período de 1993 a 1996. À luz da pesquisa de avaliação de processo, aborda as características da municipalização da merenda escolar nas suas dimensões organizacionais: dos recursos humanos, da infra-estrutura, dos insumos e das opiniões dos seus agentes implementadores, decisores e beneficiários, para aferir o desempenho do programa (o alcance das metas e objetivos) e a sua eficácia social, além das condições e fatores de êxito ou fracasso da implementação. Trata-se de um estudo de caso do programa municipal, que utilizou dados primários (entrevistas e redações de alunos) e secundários. Conclui que a descentralização da merenda ocorrida no município foi mista, resultando na fragmentação do programa quanto ao atendimento às redes de ensino (estadual e municipal). A cobertura da clientela foi ampla, detectando-se, porém problemas na qualidade, no controle e na supervisão da alimentação. Os problemas institucionais persistentes, no entanto, não minimizaram a importância do programa para gestores, diretores e usuários.

Termos de indexação: pesquisa de avaliação; programa de alimentação escolar, descentralização, alimentação escolar.

\section{A B S T R A C T}

The article evaluates the implementation process of the decentralized (municipalism) school-lunch program in Cuiabá (1993 - 1996). Guided by the process evaluation research, this article analyses the characteristics of the

\footnotetext{
1 Instituto de Saúde Coletiva, CCBS III, Universidade Federal do Mato Grosso. Av. Fermando Corrêa da Costa, s/n, 78060-900, Cuiabá, MT, Brasil. Correspondência para/Correspondence to: M.A.S. SPINELLI. E-mail: angsp@terra.com.br

2 Curso de Pós-Graduação em Saúde Coletiva, Departamento de Medicina Preventiva e Social. Faculdade de Ciências Médicas, Universidade Estadual de Campinas.E-mail: anacanesqui@uol.com.br
} 
municipalism school lunches' implementation process, in all its dimensions (organizational, personnel, infrastructure and resources). It also considered the opinions of all its agents (decision-makers and implementation agents, as well as the beneficiaries of the program), in order to compare the program objectives and goals to its performance, achievement, and social efficiency, and to conclude about the conditions and factors affecting the implementation's success or failure. This case study of the school-lunch program in the Cuiabá municipality, was based on collected primary data (interviews and children's writings), as well as secondary data. It concludes that the program decentralization had a mixed outcome and resulted in fragmentation, regarding its services to the area schools' network (state and municipal). The program covered an ample clientele, but problems were detected in the services' quality, involving the food and meals' control and supervision. Despite the persisting institutional irregularities, the program's importance, however, wasn't diminished, according to its directors, managers, and beneficiaries as well.

Index terms: evaluation research, school-lunch program, decentralization, school feeding.

\section{N T R O D U Ç Ã O}

A descentralização é um novo formato dado às políticas sociais na década de 1990, pelo governo federal, no âmbito da reforma do Estado. Este processo ocorreu num quadro de desigualdades regionais e de diferentes capacidades institucionais, gerenciais e financeiras das unidades sub-nacionais de governo. Estas condições definiram resultados heterogêneos de um mesmo programa nos estados e municípios. A descentralização se integrou à agenda reformista nacional associando-se a argumentos de construção da democracia, no sentido de ampliar as bases da participação social, da cidadania e dos direitos sociais. Por outro lado, as reformas políticas institucionais introduzidas na Constituição de 1988, redesenharam o federalismo, buscando recuperar as prerrogativas fiscais e decisórias das instâncias sub-nacionais de governos. Descentralizar, como disse Afonso' ${ }^{1}$, não é processo apenas técnico, requer, na sua completude, a redistribuição do poder político, econômico, decisório e financeiro.

O Programa de Alimentação Escolar, desde a sua origem e consolidação, foi centralizado sob diferentes agências nacionais vinculadas ao Ministério de Educação e Cultura. A descentralização de algumas políticas sociais foram previstas na Constituição Federal de 1988, entre elas os programas de apoio ao ensino fundamental, incluindo a alimentação escolar. O programa objetivava oferecer refeições capazes de cobrir de $15 \%$ a $30 \%$ das necessidades nutricionais dos escolares da pré-escola e do ensino fundamental das redes públicas e filantrópicas de ensino².

Este artigo enfoca a avaliação do processo de implementação do Programa de Alimentação Escolar descentralizado (municipalizado) em Cuiabá, capital do Estado de Mato Grosso, no período de 1993 a 1996. Tomamos como base o estudo de Spinelli ${ }^{3}$ que aborda a transição do formato centralizado para o descentralizado. A inexistência de estudos similares para o município de Cuiabá naquele momento, torna relevante a pesquisa. Trata-se da introdução de inovações e mudanças na política de alimentação escolar definidas pela Fundação de Assistência ao Estudante $^{(3)}(\mathrm{FAE})$, desde 1993, impressas pela descentralização, que se deu sob diferentes modalidades, abarcando primeiramente as capitais e municípios com mais de 50 mil habitantes.

\section{Revisão da literatura e o marco conceitual}

Autores que revisitaram a literatura de avaliação de políticas e programas sociais no

\footnotetext{
3 A FAE foi extinta em 1997, passando o Programa de Alimentação Escolar a ser gerido pelo Fundo Nacional de Desenvolvimento da Educação (FNDE).
} 
Brasil, como Figueiredo \& Figueiredo ${ }^{4}$, mostraram que os Programas de Nutrição e Alimentação foram bastante pesquisados nas políticas sociais, enfocando sobretudo os seus impactos e adequações nutricionais e menos sua formulação e implementação. As ciências sociais trouxeram, na década de 1980, contribuições à análise da implementação de políticas sociais, focalizando as dimensões institucionais, as decisões, os obstáculos e facilidades relacionados aos programas. São estudos de natureza avaliativa que incorporaram metodologias e análises próprias às ciências sociais, que fazem uma interlocução importante com a área da Nutrição e da Saúde Coletiva, em direção à construção da interdisciplinaridade diante de objetos de pesquisas comuns.

Estudos de implementação são ainda incipientes no Brasil ${ }^{5,6}$. A pesquisa nacional de descentralização do Programa da Merenda Escolar apontou o desempenho muito heterogêneo entre os diferentes portes das escolas e entre as regiões do país, em 1996. O sucesso do programa relacionou-se ao forte apoio dos diretores, registrando elevado grau de satisfação dos alunos, além de outros resultados de eficácia e de efetividade social ${ }^{7}$.

Ao reportar-se ao estudo de 1987 de Lester et al., Perez ${ }^{6}$ mostrou que, na avaliação de políticas e programas sociais, é importante distinguir os ciclos da política que compreendem: a) a formação da política (constituição da agenda, definição do campo de interesses e identificação das alternativas); b) a formulação que abarca a definição dos objetivos, metas, recursos e estratégia que serão utilizadas; c) a implementação que se constitui no momento em que a política se transforma em programas. A literatura mais recente tem apontado para uma nova fase, a de prestação de contas à sociedade (accountability) ${ }^{8}$. Cada um destes ciclos comporta modelos e metodologias avaliativas distintos, sendo que, para a implementação, adaptam-se os estudos de caso, as abordagens e metodologias qualitativas ou a combinação dos métodos quantitativos e qualitativos ${ }^{9}$.
O clássico estudo de Pressman \& Wildavsky ${ }^{10}$ introduziu a análise da implementação e demonstrou que não basta formular bem uma política para que ela automaticamente aconteça. A implementação sucede ao cumpra-se da política e envolve um conjunto de pessoas, organismos e decisões sempre em transformação para alcançar determinados resultados que, por sua vez, também se modificam no curso da implementação. Perez ${ }^{6}$ distinguiu três enfoques dos estudos de implementação: a) top-down, que privilegia as estruturas decisórias, o grau de alcance dos objetivos, os fatores que interferem nos resultados dos programas e as reformulações ocorridas; b) botton-up, que levam em consideração os comportamentos dos atores (arranjos, conflitos e valores), as características institucionais e o peso dos contextos; c) por último, aqueles que, a partir da revisão crítica das limitações de ambas as abordagens, tenderam a combiná-las e articular as etapas da formulação com a da implementação da política.

Na revisão da literatura sobre as pesquisas conduzidas nas décadas de 1980 e 1990 nos Estados Unidos, Lester et al. ${ }^{11}$ mostraram a ausência de consenso sobre o conceito de implementação e a grande heterogeneidade teórico-metodológica, o que contudo, não invalidava as contribuições dadas. Os estudos de implementação centram-se nos processos e ações, nas decisões e nos atores envolvidos (burocracia, técnicos, gestores). Diferem das avaliações de impacto, que se preocupam com os efeitos das intervenções sobre determinados problemas (de saúde ou sociais).

Draibe $^{5}$ enfatiza, na avaliação, os fatores facilitadores ou os obstáculos à implementação, que interferem nos cumprimentos das metas e objetivos propostos inicialmente. Estes fatores podem ser compreendidos "como condições institucionais e sociais dos resultados", mas não se confundem com os resultados e nem com os impactos da intervenção. Entre eles destacam-se: 1) análise da complexidade institucional e das relações interinstitucionais; 2 ) análise dos sistemas 
gerenciais e decisórios; 3) identificação dos interesses dos vários atores (gestores e implementadores); 4) ênfase nos aspectos causais dos êxitos e fracassos na operação do Programa; 5) análise da qualidade do processo e dos meios empregados (recursos financeiros, humanos e materiais).

Neste estudo, entendemos a implementação como uma das etapas da política que opera em contextos institucionais, os quais dispõem de estruturas organizacionais próprias e de um conjunto de meios, recursos e agentes, com responsabilidades e atribuições diante do programa. As organizações têm sido objeto de estudo das Ciências Sociais e das Ciências Administrativas, que as entendem sob diferentes modelos, tais como o burocrático e o das relações humanas, dentre outros ${ }^{12}$. Não se trata, neste estudo, de abordar as organizações em si, como objeto de estudo específico, mas de concebê-las como ambientes dotados de um conjunto de relações inter-institucionais, recursos, agentes, atividades, regulamentos e procedimentos, os quais são mobilizados para possibilitar que um dado programa alcance as metas propostas.

A avaliação da implementação, sob o ponto de vista de seus efeitos institucionais, enfoca os processos, os agentes e o próprio fazer da política ou de um programa. Neste sentido, o estudo privilegiou, tanto as dimensões organizacionais e o seu desempenho, quanto as dimensões do próprio programa no alcance de seus objetivos e nas opiniões dos vários agentes envolvidos (decisores e implementadores) e da clientela (alunos). Portanto, os agentes foram definidos segundo as suas posições e atribuições em relação ao programa, sendo decisores, os responsáveis pela gerência e estabelecimento de normas e procedimentos do programa e implementadores, os responsáveis pela operacionalização da merenda nas escolas (diretores e supervisores).

Este estudo pressupõe que os atores podem ou não atuar como facilitadores dos resultados do programa. Como partícipes do processo de implementação, eles acumulam conhecimento e aprendizagem que os levam a formar opiniões (julgamentos avaliativos); estas que devem ser levadas em consideração, quando se quer identificar condicionantes de êxito e fracasso dos programas. Consideramos que as opiniões dos beneficiários deveriam ser incorporadas ao estudo, como meios de aferir a legitimidade social do programa. Tanto as pessoas encarregadas da implementação, quanto os beneficiários detêm opiniões e emitem julgamentos, construídos a partir da experiência com o próprio programa, embora, quando se pensa de maneira construtivista, os significados sejam construídos pelos sujeitos sociais e informados pela experiência de vida, reportadas à sociedade.

Neste estudo estão combinadas as perspectivas objetivistas (positivista e factual) com a subjetivista (construtivista), sem que a última tenha sido o fio condutor do estudo. Esta foi aplicada apenas na interpretação de alguns dados de natureza qualitativa. O referencial adotado foi pluralista e combinou metodologias quantitativas e qualitativas ${ }^{12}$. Vale esclarecer que uma pesquisa avaliativa, por sua natureza mais operacional, visa subsidiar a gestão e sendo um tipo de pesquisa estratégica ${ }^{13}$, distingue-se dos estudos básicos e disciplinares de produção de conhecimento. Este tipo de estudo pode combinar métodos quantitativos e qualitativos, preocupando-se com processos e atividades de agentes e seus comportamentos; vale-se de documentos, observações sobre situações e processos organizacionais ${ }^{9}$; vale-se ainda de dados quantitativos do programa, usando aqueles registrados, ou produzindo-os. Este tipo de estudo representa uma tendência dos estudos contemporâneos ${ }^{14}$. Por esta razão, ao invés de prender-nos aos atributos paradigmáticos da objetividade versus subjetividade, tornando-os irreconciliáveis na prática da pesquisa, fazemos a combinação dos métodos, abraçando o que, segundo Patton ${ }^{9}$, resulta numa perspectiva pragmática. A natureza desta pesquisa avaliativa requer ainda, a compreensão e o conhecimento da lógica e da teoria embutidas na política de um programa, ou seja, conhecer sua formulação, 
estratégias e metas, consideradas o primeiro passo imprescindível da avaliação $0^{5,9}$.

\section{Metodologia e procedimentos da pesquisa}

A natureza avaliativa desta pesquisa levounos a optar pelo estudo de caso do tipo exploratório, ao invés de utilizarmos os modelos causais experimentais. Como desdobramento dos pressupostos teóricos e metodológicos e dos objetivos do estudo, a obtenção de dados visou as seguintes dimensões de análise, que coincidem com as citadas por Draibe ${ }^{5}$ : 1) organizacional: as estruturas montadas, competências e articulações inter e intra-institucionais; estabelecimento e cumprimento das rotinas e das atividades; 2) desempenho, compreendido como cumprimento das metas e dos objetivos (número de alunos atendidos, dias letivos cobertos, quantidade e qualidade da merenda servida); 3) perfil socioeconômico e ocupacional dos agentes, disponibilidade e adequação dos recursos humanos e da infraestrutura de apoio; 4) opiniões dos agentes e benificiários sobre o programa.

O uso de fontes secundárias de dados (documentos institucionais e bibliografia), combinadas com fontes primárias de entrevistas não estruturadas, feitas com ex-coordenadores e coordenadores em exercício, possibilitou apreender o desenho do programa municipal, identificando suas metas, objetivos e estratégias.

O perfil socioeconômico e ocupacional dos agentes foi obtido através das variáveis: sexo, ocupação, vínculo institucional e tempo de trabalho no cargo. Para aferir as opiniões dos agentes, solicitamo-lhes que avaliassem as várias dimensões do programa, segundo escala valorativa. Foram solicitados a opinar sobre os graus de alcance dos objetivos do programa e da adequação das estruturas organizacionais, da infra-estrutura material disponível nas escolas; a qualidade e regularidade da merenda. Opinaram ainda a respeito dos aspectos positivos e negativos do programa e do processo de descentralização e identificaram seus problemas principais.

O questionário compôs-se de perguntas fechadas e abertas. As fechadas aplicaram-se ao perfil e à obtenção dos julgamentos avaliativos. A escala valorativa empregada possibilitava ao entrevistado aferir uma nota de 1 a 4 ao item de cada pergunta, com a escolha de uma das alternativas: 1 =fraco; 2 =regular; 3 =bom; $4=$ muito bom. As perguntas abertas deram oportunidade às justificativas e facultaram aos entrevistados expressarem-se tanto sobre os problemas, como sobre os aspectos positivos ou/e negativos do Programa.

Os questionários foram aplicados a 51 agentes, classificados da seguinte forma: a) agentes decisores (5 profissionais): coordenadores e técnicos pertencentes a órgãos centrais da prefeitura e responsáveis pela formulação do programa nos seus níveis de atuação; b) agentes implementadores (41 diretores e 5 supervisores): profissionais ligados à operacionalização do programa nas escolas. O estudo abrangeu todas as escolas da rede municipal, 48 à época, obtendo-se $85,4 \%$ de respostas. Deve-se observar, no entanto, que não entrevistamos as merendeiras, que são importantes agentes da implementação do programa.

Para obter as opiniões dos beneficiários, solicitou-se aos alunos das quartas séries de três escolas municipais, que elaborassem redações sobre o tema "a alimentação na minha escola". As escolas foram classificadas segundo os critérios de localização no espaço da cidade (centro e periferia) e tamanho (grande, pequena e média de acordo com o número de alunos). Uma escola central (grande), situada em bairro tradicional, e duas escolas (média e pequena) localizadas em bairros periféricos. Segundo indicações dos implementadores, atendiam a clientelas em condições socioeconômicas diferentes. Foram obtidas 144 redações que serviram para a análise das opiniões de parcela da clientela atendida. Não se pretendeu generalizar os resultados desta análise para o universo da clientela das escolas, 
mas a análise qualitativa destas redações permitiu aquilatar as avaliações dos alunos sobre alguns aspectos de interesse para os propósitos do estudo.

No tratamento dos dados foram usadas técnicas estatísticas de freqüência simples e percentuais das variáveis mensuráveis do questionário, referentes aos perfil socioeconômico, demográfico e ocupacional dos agentes entrevistados e de seus julgamentos avaliativos, contidos nas respostas de escolhas alternativas. A análise qualitativa foi aplicada aos conteúdos temáticos dos textos redigidos pelos alunos e às frases contidas nas respostas às perguntas abertas do questionário. O recurso à análise temática permitiu decobrir núcleos de sentido, presentes nas redações/comunicações, cuja presença ou freqüência fazem sentido para o objetivo do estudo.

A análise qualitativa realizou-se após a leitura exaustiva das respostas às perguntas abertas do questionário, cujos temas mais recorrentes foram computados por suas freqüências. Na análise dos textos das redações, foram destacados apenas três temas: a importância da merenda escolar e do programa; freqüência e regularidade das refeições servidas; composição e sugestões de cardápios. Outros conteúdos identificados não foram analisados, por fugirem aos propósitos do estudo (no entanto, permitem uma análise mais ampla, deixada para um outro artigo). Estes conteúdos temáticos foram identificados, computadas as suas freqüências, separados em fichas e interpretados pelos pesquisadores.

A análise qualitativa, na perspectiva adotada, levou em consideração a compreensão dos significados, segundo as construções e experiência dos atores em uma dada situação social ${ }^{15}$. Devido à natureza avaliativa desta pesquisa restrita a um programa, os eventos a ela relacionados formam o contexto de referência dos significados e das experiências examinadas, a partir dos relatos.

\section{RES U L T A D OS}

O período estudado foi o de transição e de experimentação do processo de descentralização do Programa Nacional da Merenda Escolar, conduzido pelo governo federal. A modalidade de descentralização adotada no município de Cuiabá foi mista, mantendo a duplicidade e a independência dos programas estadual e municipal. Estas características refletiram, de um lado, a estratégia descentralizadora da FAE como um processo gradual de municipalização, não descartando a estadualização e, de outro, a falta de unificação do sistema de ensino e das redes escolares em um mesmo território, evidenciavam resistências do governo estadual à municipalização.

A adesão da prefeitura cuiabana ao processo de descentralização empreendido pelo governo federal, deu-se na gestão de 1993 a 1996, mediante convênio firmado com a FAE em 1993. O convênio garantiu o repasse dos recursos financeiros pelo governo federal ao município e o montante foi calculado sobre um valor per capita, conforme o número de alunos matriculados nas redes de ensino municipal e filantrópica. A adesão implicava atender a um conjunto de requisitos burocráticos e comprometer-se em oferecer como contrapartidas pessoal treinado, infra-estrutura, capacidade organizacional e criação do Conselho de Alimentação. Estas condições eram pouco complexas para uma prefeitura com porte organizacional como a de Cuiabá.

O Programa de Alimentação Escolar oferecido pela prefeitura ganhou uma versão local conhecida como Projeto Quitute, amplamente apoiado pelo governo municipal. Reconhecia a importância do atendimento de 30\% das necessidades nutricionais diárias dos alunos, em função da aprendizagem e da garantia de sua assiduidade à escola, pressupondo respeitar os seus hábitos alimentares e estimular os produtores locais ${ }^{3}$.

A Lei Orgânica Municipal de 1990 garantiu a responsabilidade pública pela educação 
pré-escolar, ensino de primeiro grau e educação dos adultos e instituiu a obrigatoriedade da merenda a todos os estudantes (crianças e adultos). O plano do governo municipal também propôs a autonomia da escola, cuja execução iniciou-se apenas a partir de 1996.

\section{Características do processo de implementação}

\section{As estruturas organizacionais do programa}

A Secretaria Municipal de Educação havia acumulado experiências anteriores com Programas de Merenda Escolar, desde a década de 1980. No período em estudo, ela reorganizou as suas estruturas centrais, sendo que a antiga Divisão de Apoio Escolar foi substituída pela Gerência de Apoio ao Estudante (GAE).

Este novo órgão responsabilizou-se pelo gerenciamento do programa, que se manteve centralizado nesta instância decisória. Em função de novos propósitos formulados (com respeito aos hábitos alimentares dos alunos) e dos novos mecanismos de repasse financeiro pelo governo federal à prefeitura, esta gerência articulou-se com outras instâncias da prefeitura, como o Fundo Municipal de Educação e as Secretarias da Agricultura e Abastecimento (SAA) e de Bem-Estar Social (SBES).

O Fundo gerenciou e aplicou os recursos financeiros (próprios da prefeitura e os repassados pela Fundação de Assistência ao Estudante (FAE)) e se responsabilizou pelas compras dos alimentos, sistema de concorrências públicas e prestação de contas. Enquanto coube à Secretaria de Agricultura e Abastecimento participar do sistema de abastecimento, armazenamento, controle de qualidade dos alimentos e dos estoques, à SBES coube organizar os produtores locais para abastecer o programa. A Secretaria Municipal de Educação encarregou-se de gerenciar o programa, planejar os cardápios, dar apoio técnico às escolas, acompanhar e avaliar. Esta articulação da coordenação do programa com outros órgãos da administração municipal indicam o dinamismo do programa, que foi também constatado pelo NEPP (1997), em um estudo qualitativo, envolvendo 34 municípios em oito estados ${ }^{7}$.

Os supervisores foram os mediadores entre a Secretaria e as escolas, enquanto coube aos diretores gerenciar e operar o programa nas escolas. Os coordenadores (agentes decisores) entrevistados julgaram ter ocorrido uma adequada articulação dos diferentes órgãos administrativos da prefeitura, na organização de algumas atividades do programa. Eles aderiram fortemente e destacaram a importância do fomento dos produtores locais no abastecimento direto das escolas. No entanto, não avaliaram como negativa a inexistência de articulação entre as Secretarias Estadual e Municipal de Educação para o atendimento da merenda, o que certamente propiciou a dispersão de esforços e ausência do apoio da instância estadual ao município.

Segundo a lógica montada pelo programa, o processo de implementação dependia de um conjunto de condições para a sua operacionalização e execução, tais como: a) de recursos humanos capacitados; b) infra-estrutura: local de armazenagem e de preparo das refeições, devidamente equipados; c) gêneros alimentícios que garantissem a regularidade das refeições e os aportes nutricionais; d) incorporação das rotinas pelos órgãos competentes: abastecimento, planejamento das refeições, supervisão e controle. Vejamos estes aspectos a seguir.

\section{Recursos humanos: perfil, disponibilidade e capacitação}

Dos programas da área social, a merenda escolar é um dos menos complexos quanto ao requisito recursos humanos, tanto em número como em qualificação técnica. Mas, é indispensável que o programa disponha de pessoal para gerenciá-lo, coordenar supervisionar, abastecer e executar a merenda nas escolas. 
O estudo do perfil socioeconômico e ocupacional dos agentes decisores (gerentes e coordenadores) e implementadores (supervisores e diretores das escolas) envolvidos no programa, no ano de 1995, indicou, entre os que responderam ao questionário, que $84,3 \%$ pertenciam ao sexo feminino; $64,8 \%$ vinculavam-se ao governo municipal e os demais mantinham duplo vínculo de trabalho no setor educacional (municipal e estadual). Quanto ao tempo de trabalho junto às atividades do programa, 82,3\% declararam estar no cargo há menos de cinco anos, enquanto os demais, seis anos ou mais.

Iniciada a municipalização da merenda em 1993, o fato de a maioria entrevistada ter ingressado há pouco tempo no programa, evidenciou esforços do governo municipal em destinar ao programa recursos humanos para as funções gerenciais, técnicas e de coordenação. Dos 51 profissionais que responderam os questionário, 9,8\% eram agentes decisores: técnicos das áreas administrativas centrais da SME ou de outras secretarias relacionadas ao programa; 89,8\% eram agentes implementadores - 9,8\% supervisores (professores afastados de suas funções de ensino) e 80,4\% eram diretores.

Mencionou-se apenas uma única atividade de capacitação dos profissionais, ocorrida no momento inicial da descentralização da merenda. A capacitação, um componente importante para se introduzir inovações, foi esporádica, voltada para um único segmento dos recursos humanos envolvidos na implementação do programa, as merendeiras. Falhas na regularidade da capacitação, também foram apontadas no estudo nacional do programa, afetando a consolidação de inovações?.

\section{Infra-estrutura: disponibilidade e grau de adequação}

As cozinhas foram consideradas, pelos diretores, "adequadas" ao preparo das refeições, refletindo os investimentos efetuados pela Prefeitura com reformas e alocação dos equipa- mentos (fogão, geladeira, freezer e utensílios de cozinha). A disponibilidade dos equipamentos foi confirmada por $75 \%$ dos diretores. A inadequação dos locais para o armazenamento foi apontada como dificuldade. O grau de adequação desta infra-estrutura disponível mereceu os seguintes julgamentos dos respondentes: "bom" e "muito bom" para 52,1\% deles; "regular" e "fraco" para respectivamente $17,1 \%$ e 12,2\% dos informantes. Uma pesquisa de âmbito nacional apontou que $95,8 \%$ das escolas urbanas dispunham de infra-estrutura "adequada" para confecção dos alimentos, não ocorrendo diferenças regionais neste sentido ${ }^{16}$. A ausência de refeitórios foi problema nas escolas estudadas ${ }^{16}$, como em $100 \%$ das escolas cuiabanas, segundo os diretores. Desta forma, as salas de aula, as quadras esportivas e outros locais eram improvisados como refeitórios, comprometendo as condições de higiene e dignidade requeridas à realização das refeições pelos alunos.

\section{A incorporação das rotinas pela instituição}

\section{Supervisão, controle de qualidade dos alimentos e sistema de compras abastecimento}

O controle de qualidade dos produtos destinados à merenda, o preparo e a distribuição das refeições, eram rotinas a serem observadas pela supervisão e controle, segundo as normas do programa. Os mecanismos de supervisão foram mais intensos no início do programa, incorporando-se à rotina, mas tornaram-se esparsos no ano de 1995. Um conjunto de atividades (cumprimento dos cardápios, qualidade da refeição) inerentes ao programa, foi parcialmente acompanhado na escola. As merendeiras detinham alto grau de liberdade no manejo e decisões relativas ao preparo das refeições.

Com a descentralização, o controle de qualidade dos gêneros passou a ser respon- 
sabilidade do município. No período estudado, esta atividade limitou-se às análises físico-química e bromatológica de alguns produtos industrializados, realizadas no Laboratório de Nutrição da Universidade Federal de Mato Grosso. A Secretaria de Agricultura e Abastecimento efetuou apenas a vistoria dos fornecedores. Não houve participação da Vigilância Sanitária e nenhum outro mecanismo específico foi criado, podendo-se concluir que foi parcial o controle de qualidade dos alimentos ofertados pela merenda.

A inovação introduzida no sistema de compras, foi a aquisição dos produtos in natura dos produtores locais, preferidos aos produtos industrializados. Grandes esforços foram mobilizados pela prefeitura, naquele período, para que os pequenos produtores de hortifrutigranjeiros da Baixada Cuiabana se tornassem fornecedores do programa, apesar da forte disputa dos grandes atacadistas por este mercado institucional.

Os resultados desta organização significaram a ampliação do número de Associações de Produtores (de 6 em 1993, para 64, em 1995) e de famílias de agricultores (de 444 em 1993, para 1280 em 1995) abastecedoras do programa 3 . Obstáculos legais, referidos aos requisitos das licitações, foram temporariamente contornados pela prefeitura e facilitaram a continuidade da participação de empresas não-comerciais (associações) e de pequenos produtores no abastecimento do programa, até 1995. A operacionalização do sistema de compras construído pela gerência do programa, envolvendo outras secretarias municipais, teve respostas bastante positivas, segundo os agentes entrevistados. Vianna \& Tereso ${ }^{17}$, estudando a organização do abastecimento dos gêneros para o programa em Campinas, destacaram a importância de um sistema de produção local, como facilitador do atendimento das recomendações nutricionais preconizadas pela merenda e como elemento de flexibilização da administração do programa.

O abastecimento das escolas dependia do controle dos estoques pelas secretarias das escolas, da entrega dos produtos in natura pelos fornecedores e dos demais produtos pela prefeitura, segundo o cumprimento de um cronograma. Na entrega dos alimentos perecíveis (hortaliças, frutas e leite) às escolas, ocorreram atrasos que afetaram a regularidade da merenda. No entanto, dois primeiros anos de funcionamento do programa, os problemas de abastecimento foram parcialmente solucionados.

Enquanto a Prefeitura reequipou as escolas para operacionalização do programa, as falhas no sistema de prestação de contas da Secretaria Municipal levaram a FAE a suspender o repasse dos recursos financeiros ao programa, em 1995. Este fato repercutiu em todas as fases da execução do programa, principalmente no sistema de compras e abastecimento, tendo sido um obstáculo institucional importante.

\section{Planejamento e cumprimento dos cardápios}

Dez cardápios básicos foram introduzidos por nutricionistas, combinando predominantemente produtos in natura (frutas, legumes, carne e leite) e industrializados (sucos, achocolatados, óleo, margarina e biscoito). Foram modificados, no entanto, sempre que as merendeiras não dispunham dos alimentos por falhas na rotina do abastecimento da escola.

Os diretores, ao avaliarem o grau de adequação dos cardápios ao conjunto das condições das escolas, atribuíram maior valor à adequação da infra-estrutura para o preparo das refeições e menor, ao sistema de entrega dos alimentos. Julgaram adequados os recursos humanos disponíveis para a execução dos cardápios.

\section{O desempenho do Programa}

Analisando o número de beneficiários atendidos, os registros efetuados pela SME e FAE são controversos (Tabela 1). 
Tabela 1. Número de alunos atendidos e dias letivos. Programa de Merenda Escolar - 1993 a 1996. Município de Cuiabá.

\begin{tabular}{ccccc}
\hline Ano & $\begin{array}{c}\text { Alunos } \\
\text { SME }\end{array}$ & $\begin{array}{c}\text { Alunos } \\
\text { FAE }\end{array}$ & $\begin{array}{c}\text { Dias letivos } \\
\text { SME }\end{array}$ & $\begin{array}{c}\text { Dias letivos } \\
\text { FAE }\end{array}$ \\
\hline 1993 & 32295 & - & $74 *$ & - \\
1994 & 31768 & 25212 & 148 & 120 \\
1995 & 33676 & 25508 & 180 & 90 \\
\hline
\end{tabular}

Fontes: SME Prestação de Conta,1993-199520. (*) Dados disponíveis a partir do $2^{a}$ semestre de 1993, quando se iniciou a descentralização. MEC - FAE Demonstrativo de Transferência de Recursos (1997)². SME = Secretaria Municipal de Educação; PAE = Fundação de Assistência ao Estudante.

As informações oferecidas pela SME registraram nos anos de 1994 e 1995 a ultrapassagem respectiva de $20,6 \%$ e $24,2 \%$ em relação ao número de alunos atendidos documentados pela FAE. É provável que o programa municipal tenha coberto um maior número de beneficiários em relação ao previsto pela FAE. Esta defasagem apoiou-se na sistemática do cálculo do repasse dos recursos financeiros ao programa pela $F A E$, com base no número de alunos cadastrados na Secretaria Estadual de Educação (SEE). O subregistro e as falhas no sistema de comunicação entre a SEE e a Prefeitura tiveram conseqüências negativas na disponibilidade de recursos financeiros federais para o programa. Pode-se ainda atribuir a defasagem à tendência de as prefeituras ampliarem a clientela dos programas municipais, como veremos a seguir.

Os agentes implementadores indicaram que o programa diversificou a sua clientela; sem restringir-se apenas aos alunos da pré-escola e do ensino fundamental, beneficiou outros alunos do ensino supletivo (diurno e noturno), funcionários das escolas e outros beneficiários. Este fato não é estranho a este tipo de programa, tendo sido constatado nos municípios paulistas estudados pela Fundação Prefeito Faria Lima, o que motivou as prefeituras a implantarem projetos especiais como padarias e pequenas indústrias manufatureiras de alimentos, facilitando a ampliação da cobertura para além da clientela da merenda ${ }^{18}$.

O programa propôs, como meta, cobrir 180 dias letivos segundo a recomendação da FAE. Em 1995, foram cumpridos $100,0 \%$ da meta prevista e em 1994, cumpriu-se 82,2\% do previsto (Tabela 1). Apesar da grande dimensão do programa em relação à clientela coberta, a regularidade da oferta da merenda foi uma das dificuldades enfrentadas. Dados nacionais da FAE registram a média nacional de 172 dias letivos cobertos em 19953; enquanto o programa municipal ultrapassou essa média, revelando esforços locais de melhoria no seu desempenho quanto à regularidade; houve comprometimento da quantidade e da qualidade nutricional das refeições servidas (Tabela 2).

Enquanto a FAE estabeleceu como meta cobrir 300 calorias/dia e oferecer 9 gramas de proteína diárias, os aportes nutricionais obtidos permaneceram bastante aquém do estabelecido, exceto no ano de 1996, quando se alteraram as estratégias do programa. Portanto, a flexibilização dos cardápios não garantiu que as metas de qualidade nutricional fossem atendidas, embora as quantidades per capita tenham sido significativas (Tabela 2).

Tabela 2. Quantidades globais e per capita de alimentos e aportes energéticos e protéicos diários ofertados aos beneficiários. Programa Municipalizado de Merenda Escolar - 1993 a 1996. Município de Cuiabá.

\begin{tabular}{ccccccc}
\hline Ano & Alimento $(\mathrm{kg})$ & Alimento/Aluno $(\mathrm{kg})$ & Alimento/Aluno/dia (g) & $\mathrm{kcal} / \mathrm{dia}$ & $\%$ adq. (kcal) & $\%$ adq. (kcal) \\
\hline 1993 & 85,722 & - & - & - & - & - \\
1994 & 512,805 & 20,3 & 169 & 205,2 & 8,9 & 5,6 \\
1995 & 293,918 & 11,5 & 128 & 179,5 & 7,8 & 4,3 \\
1996 & 723,408 & 24,5 & 136 & 278,7 & 12,2 & 8,0 \\
\hline
\end{tabular}

Fonte: SME Prestação de Contas 1993-1995²0. 
O programa municipal prescreveu a oferta de duas refeições diárias e o conjunto das informações prestadas pelos decisores, diretores e alunos permite afirmar que foram servidas duas refeições nos anos de 1993 e 1994. No entanto em 1995, a insuficiência dos recursos financeiros reduziu a merenda a uma única alimentação ao dia. Foi possível observar ainda, nos depoimentos dos agentes implementadores, as resistências dos diretores à meta de servir duas refeições diárias, devido à sobrecarga de trabalho que representavam ao cotidiano escolar.

\section{Dimensões institucionais do desempenho}

A modalidade de descentralização implementada pela via da municipalização, foi fortemente apoiada pelos agentes decisores e implementadores, que argumentaram a favor da autonomia de gestão do município; isto, certamente não deve descartar, em uma Federação, a importância das responsabilidades dos demais entes (estadual e federal) no apoio aos programas sociais municipais. O alijamento da instância estadual na implementação do programa, no momento analisado, deixou a prefeitura sem apoio e sem possibilidades de dividir responsabilidades no atendimento às escolas.

Do ponto de vista institucional, a municipalização revelou esforços da prefeitura para gerenciar o programa, através de suas estruturas organizacionais; estas foram atualizadas com a reforma administrativa e com a integração intersetorial (agricultura e bem-estar social) no atendimento a certas atividades do programa, elementos esses bastante positivos. No entanto, a incapacidade administrativa da prefeitura resultou na suspensão do convênio com a FAE, no ano de 1995, e obrigou o governo municipal a arcar tanto com o financiamento do programa, quanto com os esforços para cobrir às demandas já criadas - ambos insuficientes para o desempenho do programa naquele ano.
$\mathrm{Na}$ instância municipal, segundo julgamentos dos agentes decisores e implementadores, o programa teve êxito na mobilização dos produtores locais para o abastecimento, experiência esta que envolveu modificação do mecanismo das compras. Como obstáculo à continuidade daquela inovação, persistiu a inadequação da legislação de licitações, como já foi mencionado. Dificuldades similares foram relatadas por municípios paulistas ${ }^{18}$. Por sua vez, os agentes implementadores garantiram que a municipalização foi um sucesso, pelo menos nos anos de 1993 e 1994, quando, em suas opiniões, as refeições "se mantiveram mais regulares, diversificadas, balanceadas e próximas dos hábitos alimentares dos alunos", proporcionando-lhes "satisfação e prazer, pela variedade de alimentos", segundo alguns diretores. Entretanto, estas opiniões revelam mais a forte adesão ao programa e menos os resultados positivos no cumprimento das metas nutricionais, como demonstramos na análise de desempenho.

A maioria dos diretores assumiu o gerenciamento do programa nas unidades escolares e destes, apenas 7,8\% julgaram que esta atividade Ihes ocupava tempo excessivo da administração escolar. Os obstáculos institucionais afetaram o desempenho do programa em especial quanto à regularidade e qualidade da merenda servida. Houve falhas no sistema de abastecimento (em especial em 1995) devido à inobservância dos cronogramas de entrega dos gêneros e à ausência do controle da qualidade dos alimentos. Condições que apontam dificuldades nas relações interinstitucionais. O Conselho de Alimentação Escolar, exigência formal da FAE, desde 1994, foi criado em 1995, mas não havia iniciado suas atividades, até o momento desta pesquisa.

\section{Opiniões dos agentes implementadores e beneficiários}

\section{Grau de adesão e opiniões dos agentes}

A municipalização do programa foi aprovada por $100,0 \%$ dos gerentes. Entre os 
diretores 34\% aprovaram-na "integralmente", 61,0\% "parcialmente" e 4,9\% "desaprovaram", o que demonstra baixo grau de rejeição à descentralização da merenda. Tanto é que 76,2\% dos agentes implementadores concordaram que a municipalização trouxe melhorias ao programa, $9,8 \%$ julgaram que nada se alterou e para $17,1 \%$ deles, o programa piorou.

A modalidade de descentralização preferida foi a municipalização, aprovada por $65,4 \%$ dos agentes implementadores; $14,6 \%$ dos diretores foram favoráveis à forma mais radical de autonomia da escola, significando a responsabilidade integral da unidade escolar pelo gerenciamento de recursos, decisões e execução do programa. No entanto, para ser mais eficaz, esta modalidade não pode prescindir da articulação das diferentes esferas governamentais para suporte às unidades escolares ${ }^{7}$.

Quanto ao alcance dos objetivos da descentralização propostos pela $\mathrm{FAE}, 73,2 \%$ dos agentes destacaram como "muito boa" e "boa" "a adequação dos alimentos aos hábitos culturais e alimentares da região"; $22,0 \%$, avaliaram como "fraca" a regularidade no fornecimento da alimentação escolar, que afetou o desempenho e o cumprimento das metas do programa.

Na opinião dos agentes implementadores, em 1995 a regularidade do programa foi bastante afetada pela suspensão do repasse dos recursos financeiros ao município. Este fato, percebido como forte obstáculo à implementação, demandou o uso de expedientes alternativos em algumas escolas que, se valendo de donativos de alimentos dos próprios alunos, garantiram a continuidade da merenda.

Quanto ao alcance dos objetivos formulados pelo programa, os diretores destacaram, em primeiro lugar, "o incentivo ao pequeno produtor" e em último, "o atendimento aos alunos matriculados na rede municipal de ensino, com alimentação de qualidade, boa condição de higiêne e cobertura de 30\% das necessidades nutricionais". Enquanto o incentivo ao pequeno produtor foi aspécto positivo do programa, mediante a concentração de esforços institucionais integrados, a qualidade da merenda e o atendimento das necessidades nutricionais, deixou a desejar; entretanto quanto aos números de beneficiários atendidos, a abrangência do programa foi ampla.

Os diretores reconheceram que enfrentaram um dilema: admitem a importância da merenda, devido às carências materiais e sociais dos alunos, embora creiam que o programa de alimentação escolar, ao propor oferecer duas refeições diárias, transforme a escola em um grande espaço assistencial. Criticaram ainda, a redução da jornada pedagógica, pelo tempo consumido nas refeições. Mas não deixavam de reconhecer a relevância social da alimentação escolar para os alunos.

\section{Opiniões dos beneficiários}

A oferta da merenda na escola tinha um valor positivo para os alunos, na medida em que a maioria sabia da existência da fome entre eles; para eles, no entanto, o programa tinha o caráter apenas de suplementar a alimentação. Algumas afirmações, em relação à importância da merenda, extraídas das redações, são bastante ilustrativas: "porque tem muitas crianças que vão para a escola com fome e elas não tem nada para comer em casa"; "muitos desmaiam de fome, porque eu quase desmaiei"; "quando a merenda acaba, nós ficamos fracos porque tem dia que quase ninguém toma café para ir para a escola".

Há significados distintos nestes relatos: os dos alunos da escola do centro conferem importância à merenda, devido à fome das crianças em geral e, provavelmente, apenas reproduzem os conteúdos das mensagens divulgadas pelo governo municipal sobre o programa; enquanto que os relatos dos alunos das escolas da periferia, se referem à própria experiência com a fome, expressada por eles através das sensações corporais, de "fraqueza"e "desmaios", cujo significados remetem, nas 
representações das classes populares à debilidade corporal, segundo os vários estudos antropológicos feitos sobre representações de saúde e doença no Brasil ${ }^{19}$.

Quanto à regularidade das refeições servidas na escola, os relatos comparavam os momentos iniciais do programa com o atual (referindo-se ao ano de 1995), nos seguintes termos: "Antigamente nós comíamos duas vezes por dia. Na hora da entrada, era café, quase na hora da saída, almoço (...) agora está muito fraca". "O projeto Quitute foi criado para as crianças não passarem fome na escola". "Antes era um sonho (...) Estava muito bem no começo, tinha frutas e verduras. Hoje a escola não tem feito comida" (redações da escola do centro). E completam, os alunos da periferia "A merenda escolar era melhor do que agora porque vinha muita coisa boa e gostosa (...) Antes era bem melhor, era uma comida de primeira", embora uma parte deles refira-se a "gostar da merenda". Como vimos, o ano de 1995 foi de crise do programa, reafirmando-se nos relatos a falta de regularidade da oferta da merenda e a redução das refeições servidas.

Os relatos reportaram-se à monotonia e repetição dos cardápios. Os alunos da escola central mencionaram a seguinte composição: "arroz com ovo"; "arroz com mandioca", "arroz doce", enquanto os das escolas da periferia mencionaram: "sopa de macarrão e legumes"; "arroz doce"; arroz "bem temperadinho"; "arroz com ovo"; "arroz ou leite com abóbora". Os cardápios adaptaram-se à crise do programa e se distanciaram muito dos planejados. As escolas da periferia recorriam à participação dos alunos, que se referiram aos legumes trazidos de casa, para enriquecer a merenda. Invertia-se a solidariedade embutida neste tipo de programa social em "auto ajuda" dos próprios beneficiários. Nas sugestões para a composição dos cardápios estava o valor atribuído às preparações tradicionais como, farofa de banana, galinha com arroz ou "Maria Izabel" (charque com arroz) e a demanda pelos produtos industrializados (guaraná, salsichas) e por sanduíches.

\section{CONCLUSÃO}

O programa municipal de merenda escolar, dirigido às escolas municipais urbanas da cidade de Cuiabá, implantou-se de fato, no período pesquisado, embora seja provável que o seu desempenho pudesse variar, segundo o porte das escolas, suas diferentes capacidades gerenciais e disponibilidade de recursos humanos, de infra-estrutura e insumo - cuja aferição, mediante um estudo específico das escolas, a pesquisa não contemplou. A análise do desempenho mais geral do programa, demonstrou a ampla cobertura da clientela e a sua ultrapassagem, em relação à registrada pela FAE. Programas desta natureza tendem a ampliar as demandas às prefeituras, que por sua vez, mantêm o interesses em atendê-las por razões de legitimidade junto às suas bases de apoio e das necessidades dos desprovidos socialmente.

No momento de transição da descentralização da merenda, em que a FAE ainda mantinha centralizadas as normas e os recursos financeiros na instância federal, a transferência de gestão foi incompleta. O município de Cuiabá experimentou a municipalização do programa, definindo metas e estratégias próprias que foram parcialmente alcançadas no período examinado. O processo de implementação do programa apresentou problemas e descontinuidades, afetando os seus resultados.

A análise do desempenho institucional da implementação do programa, demonstrou que não basta apenas promover ajustes das estruturas centrais dos órgãos diretivos ligados ao programa, para dar conta das inovações ou de novas atribuiç̧ões. O bloqueio da prestação de contas pelo governo federal, que afetou o fluxo de recursos financeiros, refletiu a incapacidade de outras instâncias governamentais de gerenciar os sistemas de prestação de contas e comprometeu a realização do programa em 1995. Os reflexos negativos ocorreram na qualidade e regularidade das refeições servidas. A introdução do novo sistema de abastecimento, localmente criado para 
oferecer alimentos "in natura", foi uma estratégia inovadora e, mais uma vez, as dificuldades institucionais de natureza jurídica, apenas temporariamente contornadas, restringiram a sua continuidade.

Outras dificuldades identificadas no período resumiram-se à fragilidade do sistema de supervisão e à inoperância do controle da qualidade dos gêneros servidos. Já as condições de infra-estrutura (cozinhas e equipamentos) mostraram-se adequadas, com exceção do espaço para servir as refeições.

No município de Cuiabá, duas modalidades de descentralização (estadualização e municipalização) conviveram separadamente, para atender as redes de ensino estadual e municipal, registrando a ausência da articulação entre as duas instâncias governamentais. É indiscutível que a descentralização trouxe efeitos positivos, seja por ter ampliado a aprendizagem institucional das instâncias gestoras de nível central da prefeitura, que por sua vez reorganizaram-se administrativamente para apoiar o programa, seja na forma como se incorporou às escolas, evidenciada pela adesão dos diretores ao programa.

Tal fato se deve, provavelmente, ao programa propor-se a atender os hábitos alimentares regionais e por ter privilegiado os pequenos produtores da Baixada Cuiabana, integrando-os ao sistema de abastecimento e trazendo benefícios à economia local. Além deste aspecto, como vimos, os diretores reconheceram a importância da alimentação escolar, para contornar, segundo as suas opiniões, a existência da fome entre os alunos "carentes", clientela das escolas por eles dirigidas.

\section{RE FER Ê N C I A S}

1. Afonso JR. Estado e federalismo. A crise da Federação no Brasil. Ensaios 1994; 2: 321-7.

2. Ministério de Educação e Cultura. Programa Nacional de Alimentação Escolar. Demonstrativo de transferência financeira. Brasília: FAE; 1997. 5p.
3. Spinelli MAS. Alimentação escolar: da centralização à descentralização [tese]. Campinas: Unicamp; 1998. 195p.

4. Figueiredo MF, Figueiredo AMC. Avaliação política e avaliação de políticas: um quadro de referência. Análise e Conjuntura 1986; 1(3):88-106.

5. Draibe SM. Avaliação de implantação: esboço de uma metodologia de trabalho em políticas públicas. In: Barreira, MC, Brant de Carvalho MC, organizadores. Tendências e perspectivas na avaliação de políticas e programas sociais. São Paulo: PUC-SP; 2001. p.13-56.

6. Perez JR. Avaliação do processo de implementação: algumas questões metodológicas. In: Rico EM, organizador. Avaliação de políticas sociais: uma questão em debate. São Paulo: Cortez; 1998. p.65-73.

7. Núcleo de Estudos de Políticas Publicas. Avaliação da descentralização de recursos do FNDE e da merenda escolar. Síntese dos Resultados. Campinas: Unicamp; 1997. 90p.

8. Rist RC. Influencing the Policy Process With Qualitative Research. In: Denzin NK, Lincoln YS, editores. Collecting and Interpreting Qualitative Materials. 3rd ed. London: Sage Publications; 2003. p.624.

9. Patton MQ. Qualitative research \& evaluation methods. 3th ed. London: Sage Publication; 2001. p.40.

10. Pressman JI, Wildavski A. Implementation. Berkeley University of California Press; 1973.

11. Lester JP, Goggin ML. Back to the Future: the redescovery of implementation studies. Policy Curr 1998; 8(3):1-6.

12. Contandriopoulos AP, Champagne F, Denis JL, Pineault R. A avaliação na área da saúde: conceitos e métodos. In: Hartz ZMA, organizador. Avaliação em saúde: dos modelos conceituais à prática na análise da implantação de programas. Rio de Janeiro: Fiocruz; 1997. p.29-47.

13. Minayo MCS, Sanches E. O quantitativo e o qualitativo oposição ou complementaridade? Cad Saúde Pública 1993; 9(3):239-62. 
14. Greene JC, Caracelli VJ, editores. Advances in Mixed Method Evaluation: the challenges and benefits of integrating diverse paradigm. San Francisco: Jossy Bass Publishers; 1997. p 22.

15. Denzin NK, Lincoln YS. Collecting and interpreting qualitatives material. London: Sage Publications; 2003. p.597.

16. Núcleo de Estudos de Políticas Publicas. Avaliação da rede de proteção social do Ministério de Educação e Cultura. Campinas: Unicamp; 2000. 240p.

17. Vianna RTP, Tereso MJA. O Programa de Merenda Escolar de Campinas: análise do alcance e limitações do abastecimento regional. Rev Nutr 2000; 13(1):41-49.
18. Fundação Prefeito Faria Lima. CEPAM. Serviços municipais de merenda escolar em São Paulo: uma análise dos padrões de gerenciamento. São Paulo: CEPAM; 1993. 113p.

19. Canesqui, AM. Os estudos de antropologia e saúde no Brasil na década de 90. Ciênc Saúde Coletiva 2003; 8(1):109-24.

20. Secretaria Municipal de Educação. Coordenação do Programa de Alimentação Escolar. Relatório de investimento financeiro 1993-1995. Cuiabá: SME; 1995. 15p. Mimeografado.

Recebido para publicação em 31 de janeiro de 2003 e aceito em 26 de março de 2004. 